\title{
LEPROSY, ECHINOCOCCOSIS AND AMULETS: A STUDY OF A MEDIEVAL DANISH INHUMATION
}

by

\author{
D. L. WEISS AND V. MØLLER-CHRISTENSEN
}

\section{INTRODUCTION}

IN 1948 one of us (V. M.-C.) rediscovered the forgotten site of a Danish medieval leprosy hospital, St. George's Hospital (Sankt Jørgens Spital) on a farm near the flourishing market town of Naestved in southwest Sjaelland (fig. 1). It is located about one mile outside the town on the left bank of the river Susaaen, from which it is separated by a small meadow, and the old road between Naestved and Vordingborg. Over the following twenty years, he carried out a systematic excavation of the site, including a study of the skeletons of the inmates of the institution who had been buried on the grounds.

The mass of skeletal material, representing 650 people, is unique. It is the remains of the leprosy patients from the surroundings of Naestved who were housed and cared for in the hospital and for whom return to their homes was not possible under the strict isolation laws in force in Denmark. The hospital functioned from about 1250 to 1550 , about 300 years, indicating that an average of two to three persons were buried there every year. Some of the burials were in the church associated with the hospital (53), and the rest were interred in the churchyard (597) (fig. 2).

Although the hospital was used only for patients diagnosed as lepers, evidence of other diseases common to the period is also to be found. Arthritis and pulmonary tuberculosis with calcification of the pleura have been noted, similar to that seen in excavations of non-leprous populations of the same age (V. M.-C.). One unusual case in this group is reported in this paper, a young female leper with a large number of cystic calcified structures in her abdominal and pelvic cavities. It is the purpose of this paper to illustrate the problem of interpretation of these calcified structures and to indicate some questions in the evaluation of antique human pathologic material in general.

\section{DESCRIPTION}

The skeleton (Reg. No. 540, Naestved) is that of a female of approximately sixteen years of age, as dated by the tooth eruption pattern and the condition of the sutures at the base of the skull. It was found at the lowest level of the cemetery with no other skeletons below it and a more recent inhumation (Reg. No. 539) above it at a $40^{\circ}$ angle, lying over the lower limbs. The overlying inhumation is apparently associated with the disappearance of the tibiae, fibulae, and foot bones of No. 540. The skeleton lies in an east-west position next to the foundation of the old choir wall, a position usually reserved for people of rank. From its position and level, a burial date of c. A.D. 1450 is estimated.

The length of the skeleton from vertex to knee is $105 \mathrm{~cm}$. Both arms lie in a position 


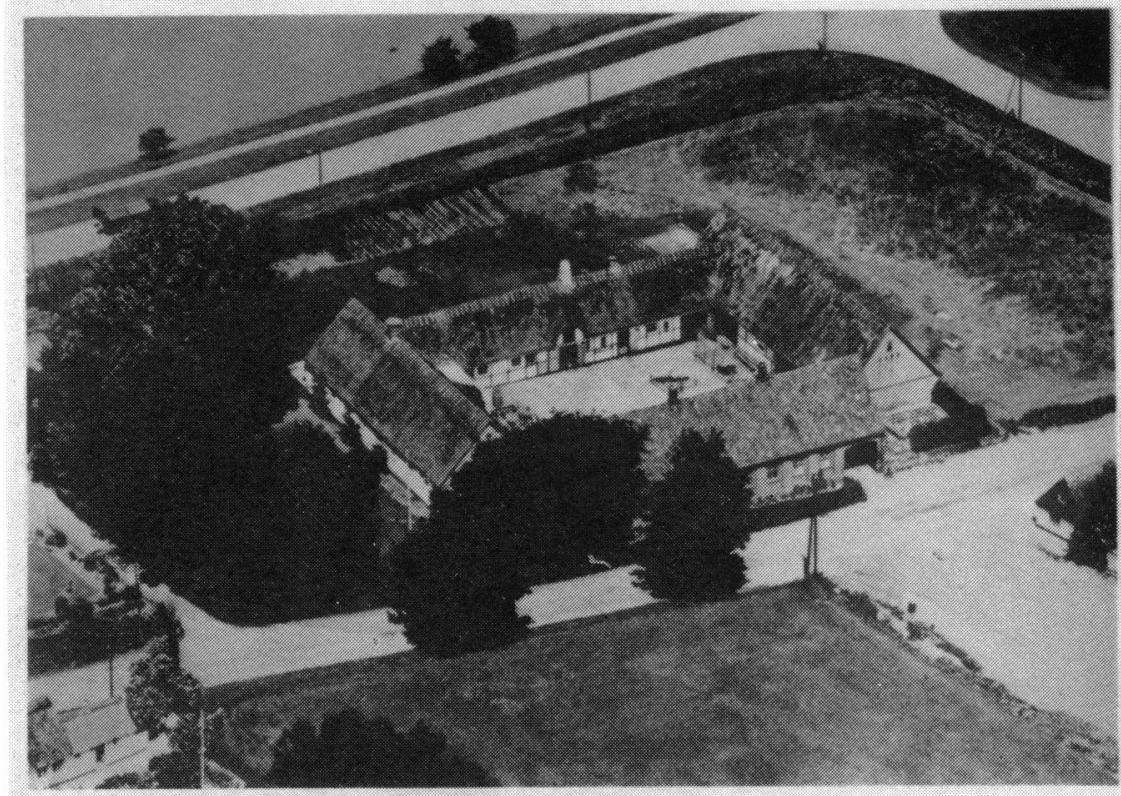

Figure 1

Site of St. George’s Hospital (Skt. Jørgens Spital), Naestved, Denmark.

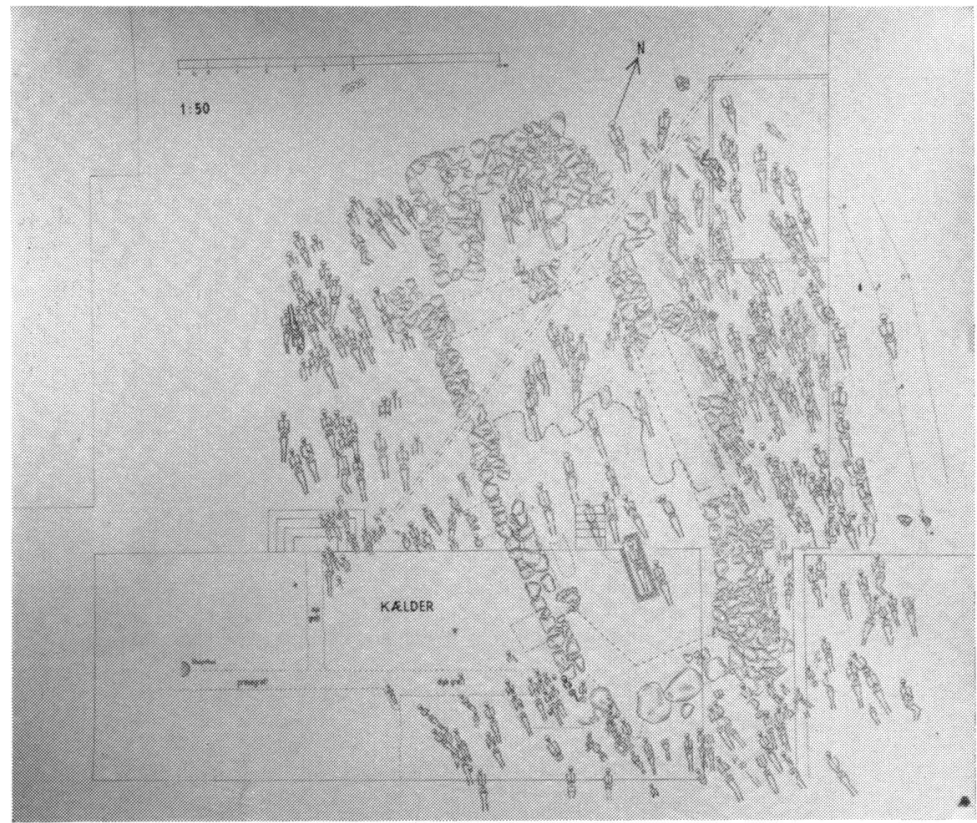

Figure 2

Plot of the burial sites, Naestved. 


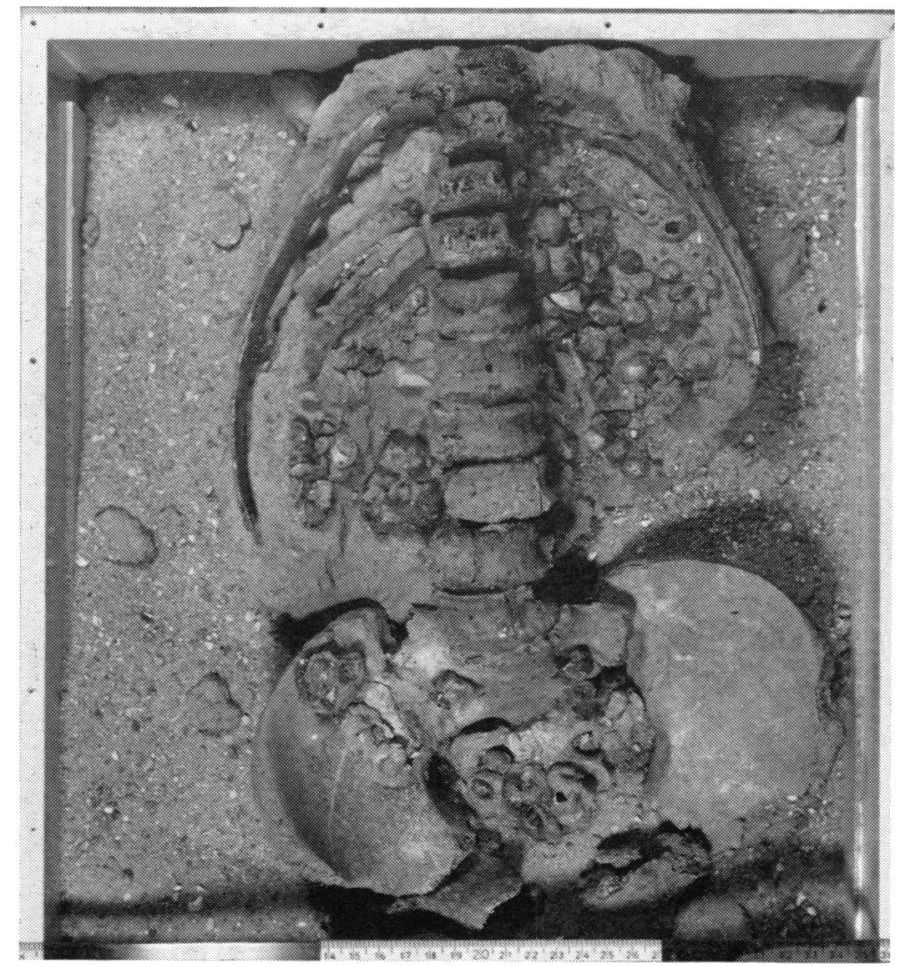

Figure 3

Abdominal area of exhumation No. 540, showing general distribution of the cysts, compact group of small bones in the right upper abdomen, scattered small bones associated with cysts in left upper abdomen. Many cysts have been removed to demonstrate the bones.

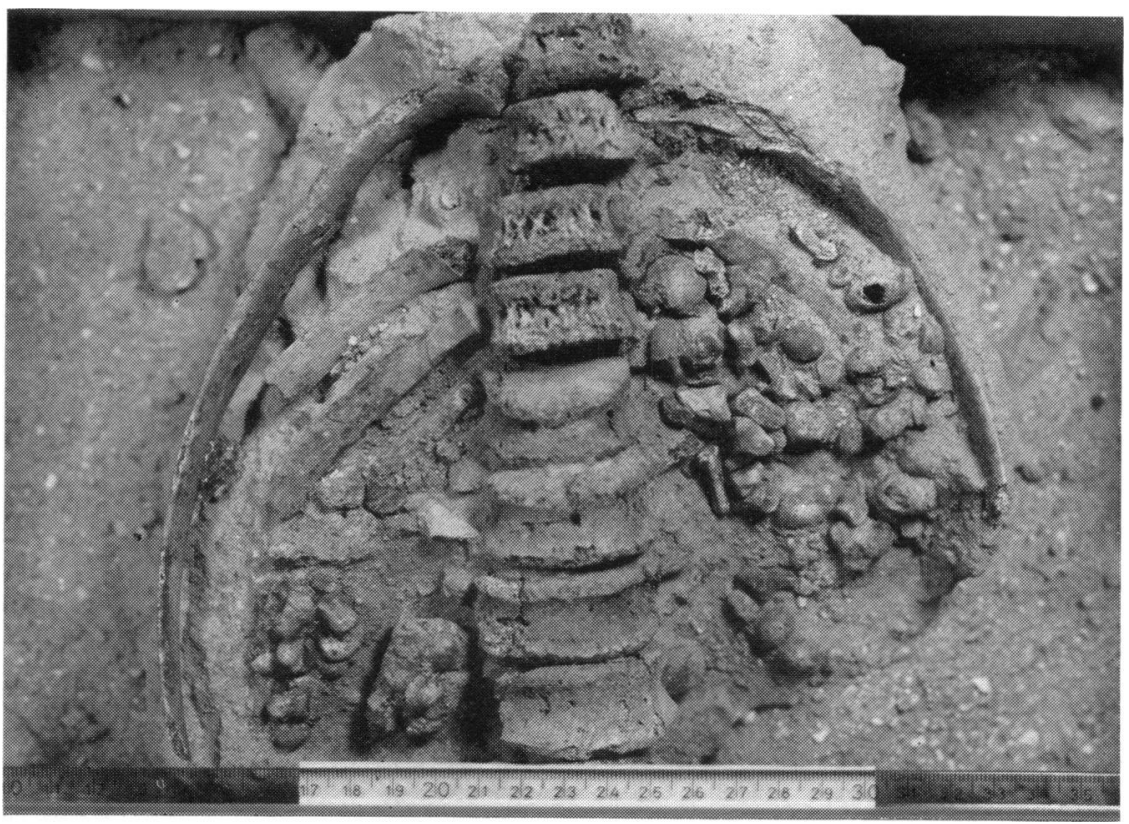

Figure 4

Close-up of upper abdominal contents (see legend, Figure 3). 


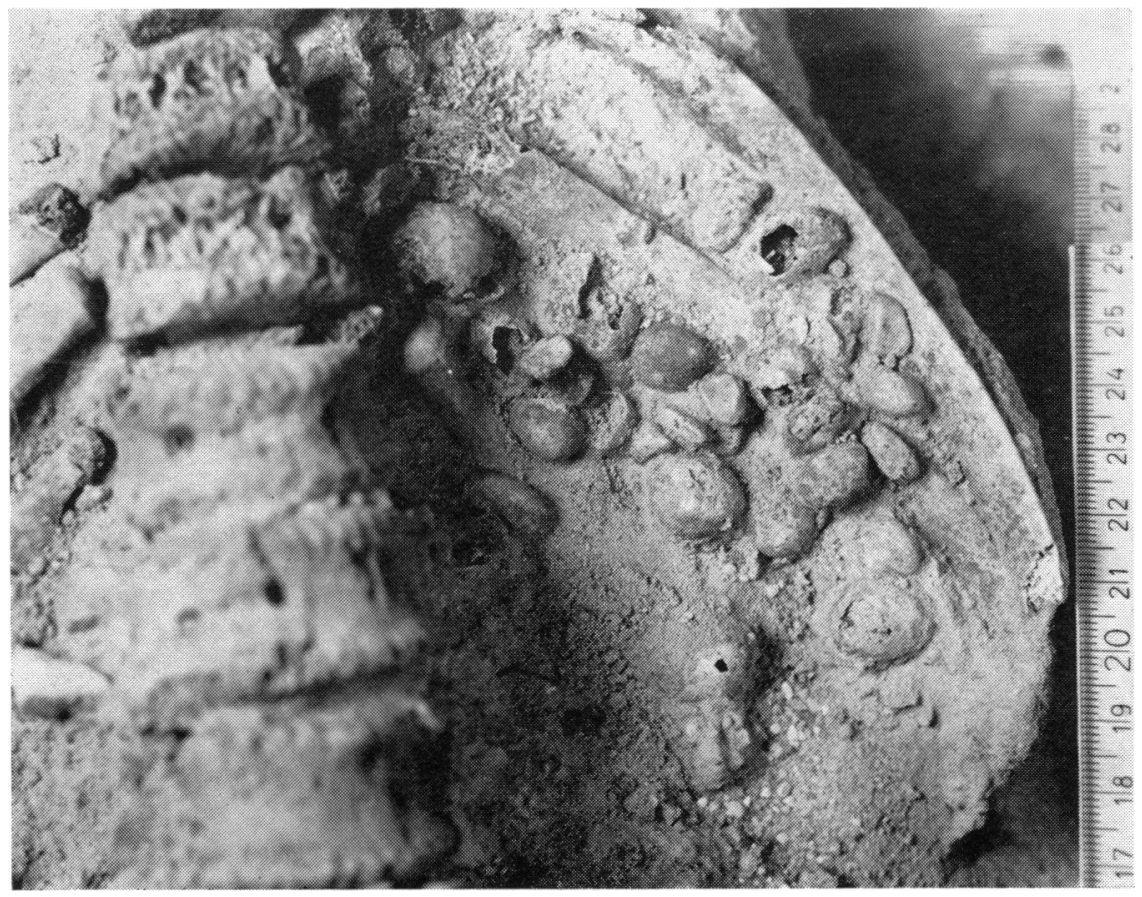

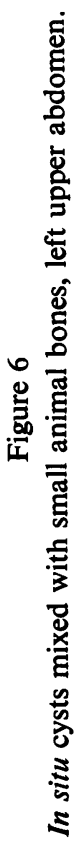

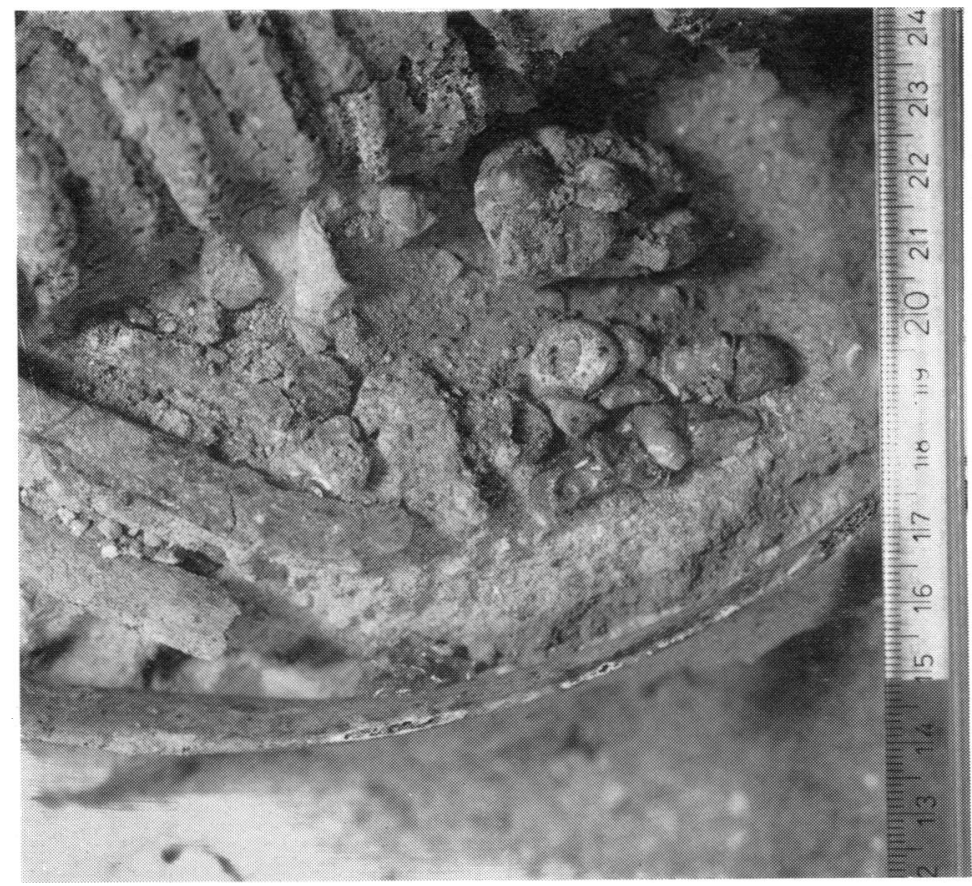

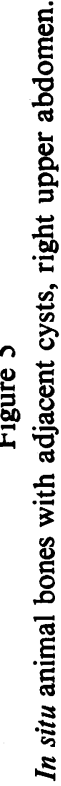




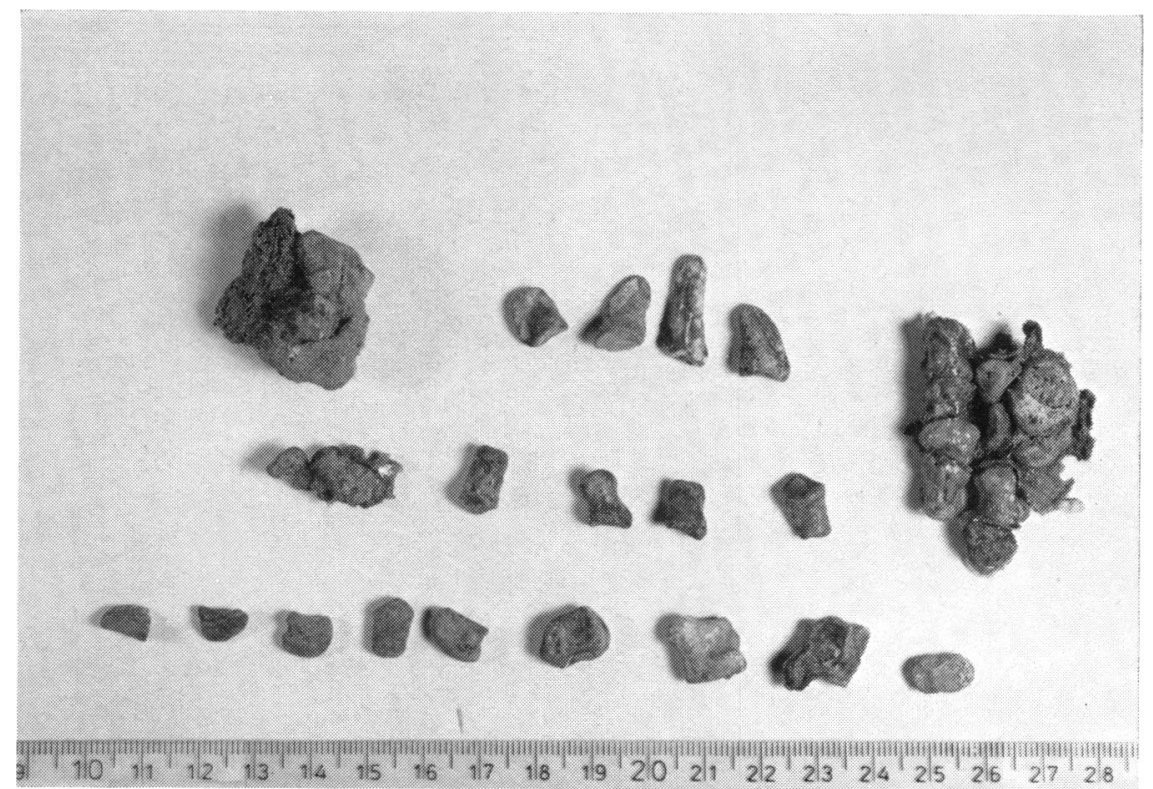

Figure 7

Small animal bones (see text).

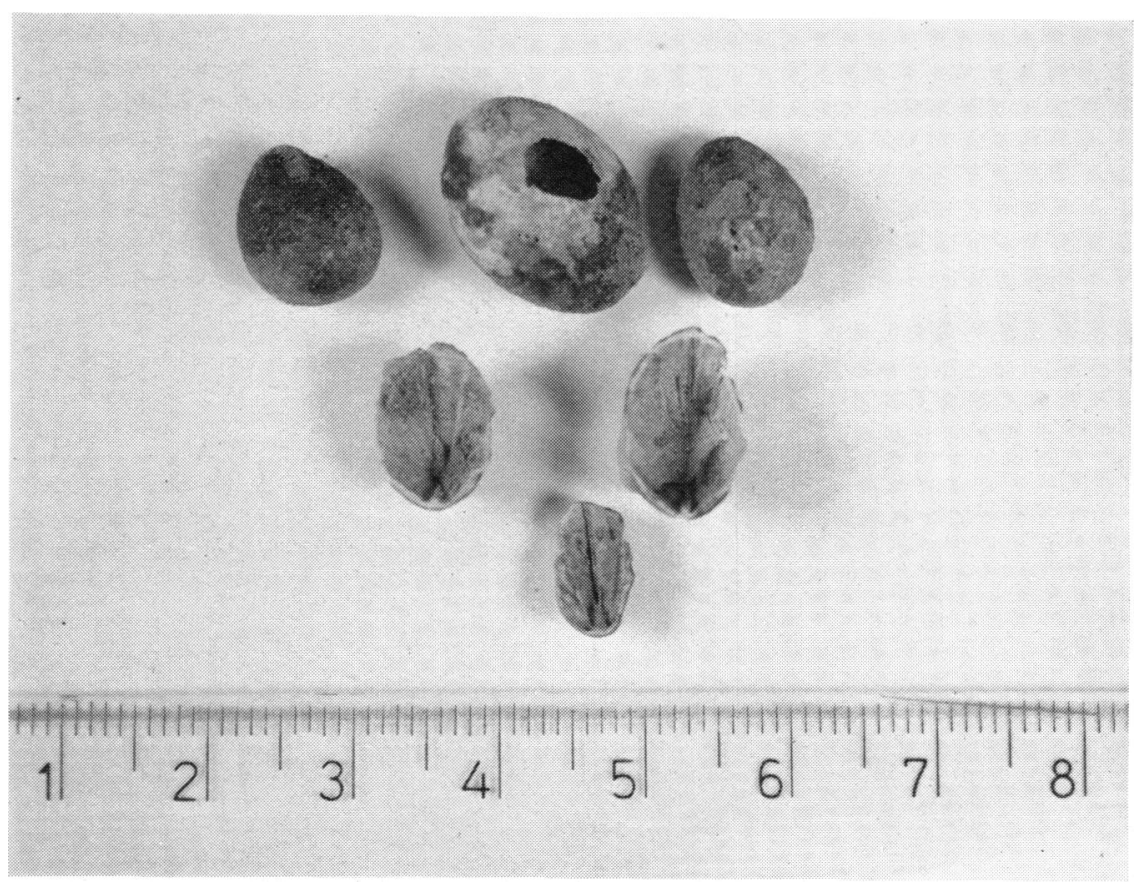

Figure 8

Calcified cysts (see text). 


\section{Leprosy, Echinococcosis and Amulets}

of maximum flexion, a characteristic position for skeletons with lesions of leprosy in the bones of the hands, presumably due to contractures caused by neural involvement. Three terminal phalanges show the trophic changes of leprosy with narrowing and spindling of the shafts, lateral concave depressions near the joints and widening of the ostia of the perforating vessels and nerves.

The vertebrae show early changes of osteoarthritis involving the axis, C3-7, T1-2, T7-8, with erosions and lipping of the articular facets and new bone formations $(T 1,7,8)$ on non-supporting surfaces. The left first rib is thin and knife-like and the right clavicle is shorter than the left with a more pronounced lateral curvature. The reconstructed vertebral column shows an exaggerated lumbar lordosis.

The bones generally are of a very light weight, out of proportion to the bone size. There is, however, no evidence of loss of cortical width, increase of trabecular structure, or increase of marrow space.

The abdominal cavity contains 72 identified calcified cystic structures and many fragments of similar cysts. They are distributed as follows: left upper abdomen, 23; right upper abdomen, 6 ; pelvis, 26 ; loose, 17 . They are all slightly ovoid in shape, with a smooth outer surface, their diameters ranging from 1.0 to $1.3 \mathrm{~cm}$. The walls of the cysts are about $1 \mathrm{~mm}$. thick. The inner surface of each cyst is marked by from 1 to 3 ridges, $1 \mathrm{~mm}$. thick, coursing from a pole to a point about one-half to two-thirds of the inner circumference distant.

Histological preparations of undecalcified cyst walls show no remaining organic material. The calcification of the wall forms a triplet structure: an inner thin layer, a middle thick layer making up most of the wall, and an irregular thin outer layer.

In addition, in the ventral portion of the right mid-abdomen, ventral to the level of the cysts, lies a compact group of tiny sesamoid, carpal and phalangeal bones which are not part of the skeleton. A similar group of bones is scattered in the left half of the upper abdomen, also lying ventral to the cysts. A total of 37 such bones is identified.

No other abnormalities of skeletal material are found. No remains of gravegoods were found, and only a few fragments of carbonized wooden pegs were recovered, probably from the casket.

\section{DISCUSSION}

The observations presented above on an exhumed female skeleton, dated approximately $\mathbf{5 0 0}$ years ago, raises a number of distinct diagnostic problems. They can be treated separately: (1) the question of leprosy as a primary disease; (2) the evaluation of the generalized alteration of bone structure; (3) the interpretation of the calcified cystic structures; and (4) the interpretation of the small bony structures situated in the upper abdomen.

(1) Leprosy. The skeleton under study had been disturbed by the placement of a later inhumation so that the legs, with the exception of the femora, have disappeared. The parts available for study for the evaluation of leprosy are the skull and hands. No changes of facies leprosa were found, but there were typical changes in the terminal phalanges of three fingers. These trophic changes assure the diagnosis of leprosy (Rf. 6, 7).

The study of the skeletons among which this case was found is illustrated in Tables 1 


\section{L. Weiss and V. Moller-Christensen}

through 3. Table 1 shows the distribution of skeletal material by age and sex. 178 skeletons were so incomplete that determination of sex was doubtful and it was equally impossible to ascertain whether bone changes due to leprosy were present. The remaining 472 skeletons were complete enough so that a diagnosis based upon changes in the skull and/or hands and feet was possible (Table 2). The juvenile age group most frequently showed changes $(83.6 \%)$. The bone lesions were almost equally distributed between males $(71.1 \%)$ and females $(76.6 \%)$. However, among the 151 female leprosy skeletons $63.3 \%$ were juveniles or adults, whereas only $36.9 \%$ of the 160 male skeletons belong to these age groups. This suggests that the female leprosy patients diagnosed and housed in this hospital died at a younger age than the males. If the average age of death is calculated, the females died at an average age of 30.1 years, while the males lived to an average age of 36.5 years, a difference of 6.4 years. Those skeletons showing no bone changes of leprosy lived slightly longer (males 38.2 years, females $\mathbf{3 1 . 0}$ years). Corresponding figures from a non-leprous population from the same period indicate that the average life span for men was $\mathbf{4 0 . 3}$ years, and for women 39.5 years.

Table 3 shows the correlation between facies leprosa and specific changes due to leprosy in the hands and feet of 185 skeletons in which there was adequate skeletal

TABLE I

Age and sex of 650 skeletons from St. George's Hospital, Naestved

\begin{tabular}{l|c|c|c|c}
\hline \multicolumn{1}{c|}{ Group } & Average Age & Sex & Number & $\%$ \\
\hline Infant I & 5 & U & 26 & 4.0 \\
Infant II & 10 & U & 26 & 4.0 \\
\hline Juvenile & 20 & M & 11 & \\
& & F & 46 & 11.1 \\
\hline Adult & 30 & U & 15 & \\
& & M & 70 & \\
& & U & 100 & 33.7 \\
\hline Mature & 40 & M & 165 & \\
& & F & 79 & 44.0 \\
\hline Senile & 60 & U & 42 & \\
& & M & 11 & \\
& & U & 6 & 3.2 \\
\hline
\end{tabular}

* $M=$ male; $F=$ female; $U=$ unknown. 


\section{Leprosy, Echinococcosis and Amulets}

material for a complete study. $71.3 \%$ had both types of pathology, $2.2 \%$ had only changes in the skull, and $26.5 \%$ had changes due to leprosy only in the hands and feet. It is to this latter group that the reported case belongs.

(2) General abnormality of bone. The skeletal variations can be summarized as including a very small stature for the bone age, early spinal osteoarthritis, exaggerated lumbar lordosis, and unusually light-weight bones. The decrease in bone weight is not accompanied by obvious loss of cortical bone, increase in marrow space or increase in trabecular structure. It appears to be a general phenomenon which may be related to the short stature. A prolonged period of physical inactivity may have produced an early stage of osteoporosis which cannot be diagnosed from the available material.

TABLE II

Leoprosy changes in $\mathbf{4 7 2}$ skeletons, skulls and calvaria by age and sex, St. George's Hospital, Naestved

\begin{tabular}{|c|c|c|c|c|c|c|c|c|c|}
\hline \multirow[t]{2}{*}{ Group } & \multirow[t]{2}{*}{ No. } & \multicolumn{3}{|c|}{ Facies Leprosa* } & \multirow[t]{2}{*}{ Hands } & \multirow[t]{2}{*}{ Feet } & \multicolumn{3}{|c|}{ Total Leprosy* } \\
\hline & & + & poss. & - & & & + & poss. & - \\
\hline $\begin{array}{l}\text { Infant I } \\
\text { Infant II }\end{array}$ & $\begin{array}{l}22 \\
28\end{array}$ & $\begin{array}{r}2 \\
16\end{array}$ & $\begin{array}{l}0 \\
6\end{array}$ & $\begin{array}{r}20 \\
5\end{array}$ & $\begin{array}{l}0 \\
5\end{array}$ & $\begin{array}{l}0 \\
3\end{array}$ & $\begin{array}{r}2 \\
16\end{array}$ & $\begin{array}{l}0 \\
6\end{array}$ & $\begin{array}{r}20 \\
6\end{array}$ \\
\hline $\begin{array}{l}\text { Male } \\
\text { Juvenile } \\
\text { Adult } \\
\text { Mature } \\
\text { Senile }\end{array}$ & $\begin{array}{r}12 \\
60 \\
145 \\
8\end{array}$ & $\begin{array}{r}8 \\
43 \\
70 \\
4\end{array}$ & $\begin{array}{r}3 \\
6 \\
30 \\
1\end{array}$ & $\begin{array}{r}1 \\
11 \\
45 \\
3\end{array}$ & $\begin{array}{r}8 \\
20 \\
33 \\
3\end{array}$ & $\begin{array}{r}3 \\
22 \\
45 \\
5\end{array}$ & $\begin{array}{r}11 \\
48 \\
94 \\
7\end{array}$ & $\begin{array}{r}1 \\
2 \\
16 \\
0\end{array}$ & $\begin{array}{r}0 \\
10 \\
35 \\
1\end{array}$ \\
\hline $\begin{array}{l}\text { MALE } \\
\text { TOTAL }\end{array}$ & 225 & 125 & 40 & 60 & 64 & 75 & 160 & 25 & 46 \\
\hline $\begin{array}{l}\text { Female } \\
\text { Juvenile } \\
\text { Adult } \\
\text { Mature } \\
\text { Senile }\end{array}$ & $\begin{array}{r}43 \\
89 \\
60 \\
5\end{array}$ & $\begin{array}{r}32 \\
54 \\
37 \\
2\end{array}$ & $\begin{array}{r}4 \\
11 \\
10 \\
1\end{array}$ & $\begin{array}{r}7 \\
24 \\
13 \\
2\end{array}$ & $\begin{array}{r}10 \\
21 \\
22 \\
3\end{array}$ & $\begin{array}{r}10 \\
30 \\
25 \\
4\end{array}$ & $\begin{array}{r}35 \\
65 \\
46 \\
5\end{array}$ & $\begin{array}{l}3 \\
7 \\
6 \\
0\end{array}$ & $\begin{array}{r}5 \\
17 \\
8 \\
0\end{array}$ \\
\hline $\begin{array}{r}\text { FEMALE } \\
\text { TOTAL }\end{array}$ & 197 & 125 & 26 & 46 & 56 & 69 & 151 & 16 & 30 \\
\hline $\begin{array}{c}\text { TOTAL } \\
\%\end{array}$ & 472 & $\begin{array}{c}268 \\
56.9\end{array}$ & $\begin{array}{l}72 \\
15.2\end{array}$ & $\begin{array}{c}132 \\
27.9\end{array}$ & $\begin{array}{c}125 \\
26.4\end{array}$ & $\begin{array}{l}147 \\
31.1\end{array}$ & $\begin{array}{l}329 \\
69.7\end{array}$ & $\begin{array}{c}41 \\
8.7\end{array}$ & $\begin{array}{l}102 \\
21.6\end{array}$ \\
\hline
\end{tabular}

* $+=$ definite changes; $-=$ no changes. 


\section{TABLE III}

Bone changes diagnostic of leprosy: correlation between facies leprosa (F.L.) and specific changes of leprosy in the hands and feet

\begin{tabular}{l|c|c|c|c}
\hline Group & Sex & $\begin{array}{c}\text { F.L.with } \\
\text { changes in } h / f\end{array}$ & F.L. alone & $\begin{array}{c}\text { Changes in } \\
\text { h/f alone }\end{array}$ \\
\hline Juvenile & M & 8 & 1 & 3 \\
& F & 17 & 1 & 8 \\
& Total & 25 & 2 & 11 \\
\hline Adult & M & 21 & 1 & 2 \\
& F & 24 & 1 & 4 \\
& Total & 45 & 2 & 6 \\
\hline Mature & M & 31 & 0 & 19 \\
& F & 24 & 0 & 10 \\
& Total & 55 & 0 & 29 \\
\hline Senile & M & 4 & 0 & 2 \\
& F & 3 & 0 & 1 \\
& Total & 7 & 0 & 3 \\
\hline TOTAL & & 132 & 4 & 49 \\
$\%$ & & 71.3 & 2.2 & 26.5 \\
\hline
\end{tabular}

Such prolonged inactivity could have been produced by leprous lesions of the feet. In the absence of these bones, this can only be offered as a theoretical possibility.

Another possible explanation may lie in the frequent renal amyloidosis seen in lepromatous leprosy. The consequent chronic nephritis may be related to abnormalities of calcium metabolism with depletion of mineral from the skeleton.

(3) Calcified cystic structures. To evaluate the significance of the peculiar cystic structures found in this case, the unique structure of the individual cysts and their distribution must be considered. The diameters of the cystic structures vary only slightly, their most impressive feature being the regularity of their overall appearance. Some of the cysts are rounded, but most have a slightly tented structure producing a distorted ovoid shape. The cyst walls, now consisting solely of calcareous material devoid of identifiable organic matrix, are very thin and fragile, marked on their inner surface by thin trabecular-like ridges.

The distribution of the cysts is restricted to the abdominal cavity of a single inhumation in the cemetery. The majority are clustered in the left renal-splenic area, but some are also found in both lumbar fossae and in the pelvis. Some lie in relation to the gall bladder area, others lie near the sacro-iliac joints bilaterally and near the 


\section{Leprosy, Echinococcosis and Amulets}

sacro-coccygeal junction. No cysts are present in the chest or within the bones. No comparable lesions are found in other exhumations in the excavated area.

The calcification was almost unquestionably an ante-mortem phenomenon. Radiological and chemical analysis shows the presence of calcium carbonates and phosphates in a pattern which suggests replacement of the original organic matrix of the cyst, rather than the random encrustation which might be expected from the post-mortem action of soil salts.

The initial impression of a prominent grouping of cysts in the left renal area, suggesting the outline of a kidney, led to a consideration of the possibility of multicystic disease of the kidney. Calcification of simple, single, large renal cysts has been noted both pathologically and radiologically. However, such cases have shown no more than partial, thin, plate-like areas of calcification. None has been reported in the form of complete calcification of the cyst. No instance of multicystic disease of the kidney with generalized calcification of the cysts has been found in a review of the literature. In the present case, although the structure and size of the cysts in the left renal area could be interpreted as a variety of multicystic renal disease, and the contralateral cysts could have been in the right renal area originally, this diagnosis could not account for the cysts in the pelvic area. Furthermore, the universal calcification of the cysts bears no relationship with the known course of this disease.

A calcified neoplasm of ovarian or urinary tract origin presents a second possible consideration. This requires the assumption of a cystadenocarcinomatous type of malignancy with generalized abdominal metastases. Although calcification of such neoplasms have been reported, they are not as universally calcified as in the present case, nor are the cystic structures so uniform and thin-walled. Another possible tumour which is characterized by its cystic form is an hydatidiform mole. The trabeculated internal structure of the cysts and their generalized calcification again militates against this diagnosis.

Both mesenteric cysts and pancreatic cysts may calcify and may present wall structures similar to that seen in the present case, but the large number and the distribution of the cysts, as well as the regularity of their dimensions makes this diagnosis unlikely.

A far more plausible explanation of the presence of the calcified cysts is that they represent the cysts of a parasite which have undergone calcification intra vitam. Parasites which may produce such cysts during their life cycles fall into the group of Taenioiodea, of which Echinococcus and Taenia are the most important species which infect man. Multiple echinococcal cysts with thin, trabeculated walls may develop widely throughout the abdominal cavity and may calcify $(R f .3)$.

The structure and size of multiple daughter cysts developing after trauma to a primary cyst conforms to the characteristics of the cysts seen in this case. The generalized abdominal distribution is not unusual following rupture of an hepatic primary cyst, although the shock associated with rupture and release of the cyst contents is frequently severe and may result in death of the patient without the time necessary for subsequent calcification.

Echinococcal disease has been present in Scandinavia for many centuries. Thomas Bartholin observed 'water-clear' egg-like lesions in slaughtered pigs in Copenhagen in $1653(R f .1)$. It was reported as a disease of humans in the first official autopsy 


\section{L. Weiss and V. Moller-Christensen}

conducted in Iceland in 1761. Seventy-four human cases were collected in a report published in $1882(R f .5)$. Reference to a disease which may be similar is found in Thorlak's saga from the twelfth century.

Alternatively, infestation with the larval form of Taenia is a diagnostic possibility, the disease presenting with multiple cysticerci which have undergone calcification. In man, Taenia solium is the principal offender, the peritoneal cavity being a most unusual site of involvement. The size of the calcified cysts seen in this instance is larger than those found in the typical case of human cysticercosis. This fact and their exclusive abdominal distribution decreases the likelihood of human cysticercosis as the explanation of the findings.

On the other hand, Taenia are common infestations of a variety of domesticated and wild animals. Taenia pisifornis is a common tapeworm of dogs and cats. The intermediate host, the rabbit, supports the development of the larvae in its liver, whence they migrate to the abdominal cavity of the animal, become attached to the mesentery, and develop into fully formed cysticerci which may undergo calcification. Such cysts are in many ways similar to those seen in the case under discussion $(R f .2,4$, 8). If this type of Taenial cysticercosis is to be considered in the differential diagnosis, a most unusual explanation for its presence must be sought, as this specific species of parasite is not seen in man. A remote possibility is that an animal infested with Taenia pisiformis was accidentally introduced into the area of the previous inhumation, perhaps by disposal of the remains of a diseased animal, originally intended for the pot. Thereupon the remains of the two bodies would have had to intermingle with extraordinarily precise localization to create a novel kind of pseudopathology $(R f .9)$.

The same sequence of events would have to be considered in the case of $T$. solium infestation of the domestic pig, were it not for the fact that the size of the cysts in the reported case are much larger than those of cysticerci of the pig.

In the case of either type of animal infestation, the presence of animal bones associated with the cysts would be expected. Animal bones were, in fact, present, but of such types as to exclude the possibility of their association with the cysts in vivo. They are discussed below.

(4) Upper abdominal bony structures. Two groups of tiny bones were located in the upper abdomen, one being a compact group of multifaceted structure ventrally with small longer bones facing dorsally lying in the area of the gall bladder. The second group were not as compactly clustered, lying in the left upper abdomen. Careful study and radiological examination revealed that each group was composed of 21 sesamoid and pisiform bones of a sheep, combined with 16 phalangeal bones of a small pig. No other animal bones were discovered.

This odd combination of the bones of the feet of two domesticated animals, carefully arranged so that one set appears on either side of the abdomen of an interred leper, suggests that they were so placed for some therapeutic or magical purpose. The possibility that they were eaten just before death and are now found in the position of intestinal tract is unlikely, since it would not account for the apparently purposeful combinations of bones from the two animals. If they were amulets, as seems most likely, the combination of animal bones could be explained by at least two different assumptions. The first is that they were provided to the patient with the representation 


\section{Leprosy, Echinococcosis and Amulets}

that they were something other than what they in reality were. The history of the manufacture of sacred relics is sad testimony to the cupidity of man! The amulets may have been of this type.

An alternative possibility is that a magical amulet was intentionally prepared from the two animals, perhaps based upon specific religious beliefs. The pig is frequently consecrated to St. Anthony, whereas the sheep or lamb represents Christ. It would not be strange if the leprous patient sought relief from this powerful combination.

The weight of the evidence leads us to conclude that the case is one of a young female leper who had simultaneously been suffering from a parasitic infestation, most probably Echinococcus granulosus, in the form of generalized abdominal distribution of daughter cysts. She had survived the episode of dissemination, whereafter the cysts had undergone calcification. She was buried with a pair of amulets made of sheep and pig foot bones.

This case is presented in detail to illustrate the need for an appreciation of both human and animal pathology in the interpretation of antique human disease, both considered in the light of the social customs of the time. In addition, this is the first known case of echinococcal disease recognized by the examination of human remains from medieval Scandinavia.

\section{ACKNOWLEDGEMIENTS}

The authors wish to acknowledge the help of Prof. Asboe-Hansen, chemistry, Prof. G. Thomsen and Dr. H. G. Davidsen, radiology, Prof. G. Theilum, pathology, Prof. L. Bodker, folklore, Praep. U. Møhl, comparative zoology, Mr. O. Christensen, photography, and Mr. J. Starrs, histologic preparations.

\section{REFERENCES}

1. Bartholin, T., Historiarum Anatomicarum Rariorum, Centuria II, Historia LXVII, Hafniae, 1654, p. 255.

2. Benonng, D. L., Textbook of Clinical Pathology, New York, Appleton Century, 1942, pp. 438-39.

3. Cramsern, G., 'The Roentgen diagnosis of echinococcus tumors', Acta Radiologica, Suppl. VI, 1928.

4. Gorze, J. A. E., Versuch einer Naturgeschichte der Eingeweidewürmer theirische Korper (1782), cited by H. A. KRers, 'Wurmkrankheiten beim Tier', Ciba Zeitschrift, 1937, $5,1758-61$.

5. JoNassin, J., Ekinokok Sygdommen, Copenhagen, 1882.

6. Lвchit, M., Etude des Mutilations lépreuses, Paris, Masson, 1961, p. 22.

7. Møllar-Cerristzensen, V., Ten Lepers from Naestved in Denmark, Copenhagen, 1953, pp. 89, 109, 142.

8. REDI, F., Osservazioni intorno agli animali viventi, che se trovano negli animali viventi, Florence, 1684.

9. Werus, C., 'Pseudopathology', in D. Brothwell and A. T. SANDison (eds.), Diseases in Antiquity, Springfield, Illinois, C. C. Thomas, 1967, pp. 10-11. 